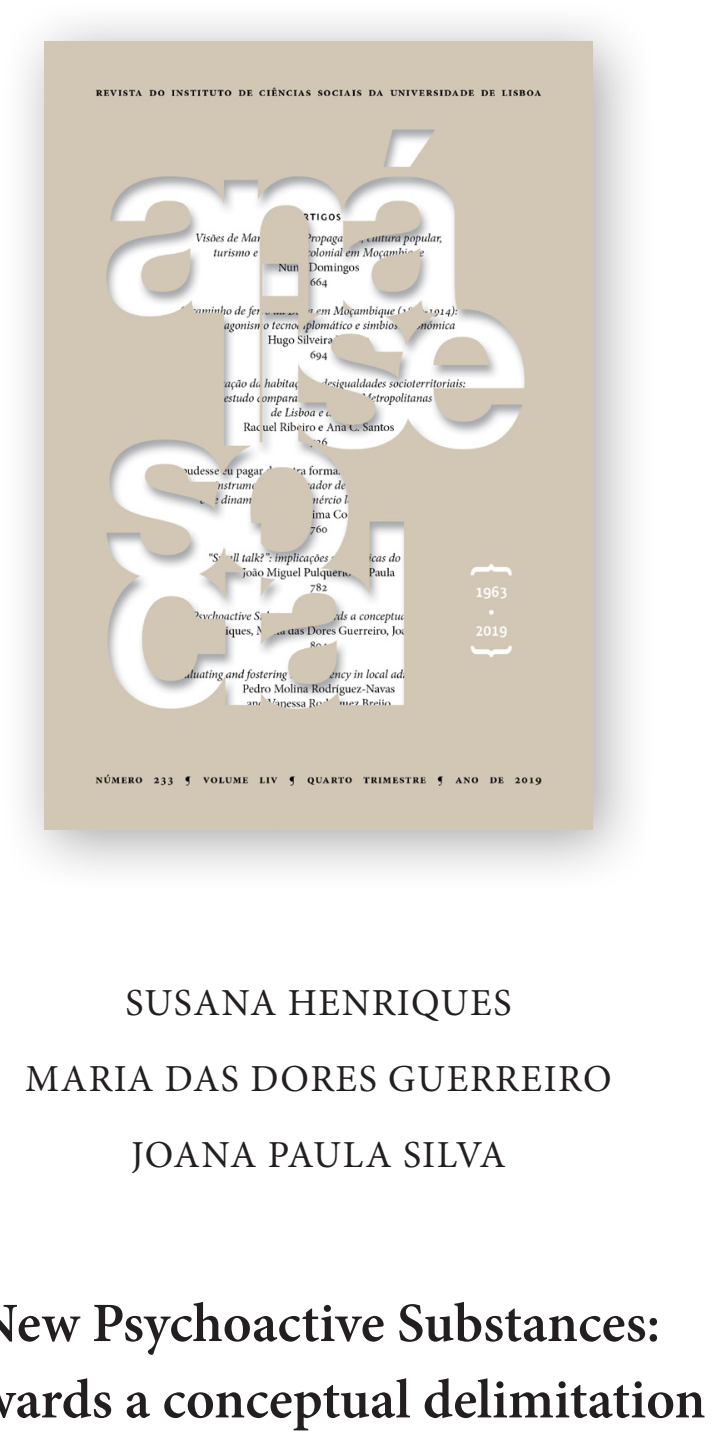

\title{
New Psychoactive Substances: towards a conceptual delimitation
}

\author{
Análise Social, LIV (4. $\left.{ }^{\circ}\right), 2019$ (n. $\left.{ }^{\circ} 233\right)$, pp. 804-826 \\ https://doi.org/10.31447/ASO0032573.2019233.06 \\ ISSN ONLINE 2182-2999
}


Análise Social, 233, LIV $\left(4 .^{\circ}\right), 2019,804-826$

New Psychoactive Substances: towards a conceptual delimitation. New Psychoactive Substances (NPS) are a relatively recent phenomenon characterized by continuous expansion throughout more or less the entire world in the last decade. They include a diversity of natural or synthetic substances that are not yet on official lists and whose great variety and rapid transformations make the NPS concept itself hard to define. Methodologically combining qualitative methods in order to present a problematized systematization of national and public policies, and quantitative ones presenting the results of a survey applied to users of NPS in Portugal, the paper contributes to a more precise definition of NPS and their effects and to know about the evolution of the applicable legal framework.

KEYWORDS: New Psychoactive Substances; conceptualization; public policies; virtual dimension.

As Novas Substâncias Psicoativas (NSP): discussão conceptual. O fenómeno das Novas Substâncias Psicoativas (NSP) é relativamente recente e caracteriza-se por um crescimento contínuo na última década, um pouco por todo o mundo. Inclui-se aqui uma diversidade de substâncias naturais ou sintéticas, que não se encontram ainda enquadradas nas listagens dos organismos oficiais. A sua grande variedade e rápida transformação configuram dificuldades de delimitação conceptual. Com base numa estratégia metodológica que combina métodos qualitativos, na sistematização problematizada das políticas públicas nacionais e quantitativos, nos resultados de um questionário aplicado a consumidores portugueses destas substâncias, o artigo apresenta um contributo para a definição e evolução do enquadramento legal do fenómeno, das substâncias e dos seus efeitos.

PalaVras-chave: Novas Substâncias Psicoativas; discussão conceptual; políticas públicas; dimensão virtual.

https://doi.org/10.31447/ASO0032573.2019233.06 


\section{New Psychoactive Substances: towards a conceptual delimitation}

\section{INTRODUCTION}

New Psychoactive Substances (NPs) are a relatively recent phenomenon characterized by continuous expansion more or less all over the world in the last decade. They include a variety of substances that can be either natural or synthetic and are not yet on the lists published by official entities, because their effects have not yet been tested and because they enter the market so quickly (EMCDDA, 2014). NPS are thus a threat to public health (EMCDDA, 2011), particularly for young people, who account for most of their users (EMCDDA, 2015; 2016). In general these substances include: synthetic substances created to mimic the effects of conventional substances and thereby circumvent the legal restrictions in the drugs field; substances that were developed in pharmaceutical laboratories, but for some reason were either not put on the market as medicines, or were marketed but then withdrawn; and natural or synthetic substances sold with the indication that they are not for human consumption (examples include bath salts, plant fertilizers, incense). These psychoactive substances are constantly appearing, and are called "new" partly because they are compounds that have just been created or recreated, but also because they have only recently arrived on the drug market. They can be chemical innovations per se, or the way in which their components are used can have recently changed.

This dynamic and continuous ability to transform, which characterizes the new psychoactive substances field, is the subject of this article, because it is what makes NPS difficult to define and conceptually delimit, and thus in turn imposes constraints on the development of knowledge about the topic. This is especially true of the applicable legal framework, levels of prevalence, 
and consumption patterns. We have experienced these difficulties first-hand as part of the project "NPS: Transnational project on different user groups, user characteristics, extent and patterns of use, market dynamics, and best practices in prevention - NPS:Trans". This study was undertaken within the remit of a transnational and interdisciplinary EU-funded research project (Benschop et al., 2017) in six Eu countries: Germany, Hungary, Ireland, the Netherlands, Poland, and Portugal. The results will enable us to offer a number of illustrations of the Portuguese case throughout this article. Having said this, although the article focuses on the Portuguese context, our reflection on the delimitation of the NPS concept will necessarily take account of the international framework in general and the current European guidelines in particular.

NPS derive their particularities from the dynamics of both the drug markets and the overall consumption of substances in today's networked societies. In other words, one of the characteristics of a networked society (Castells, 2002) is linked to the way the latter not only influences the dynamics of legitimate sectors of the economy, but also the way it affects developments in the illicit market. Factors such as low-cost travel, the absence of hard borders between EU states, and mobility programs like Erasmus mean that it has never been this easy for people to move around. Never before have flows of information and interaction been so widespread and accessible. These two groups of factors - personal mobility, and flows of information and interaction - have huge impacts on the markets, in this case the market for illicit substances in general and NPS in particular (EMCDDA, 2016a).

In order to address the complex questions involving new psychoactive substances, we must therefore begin by giving a general overview of the public debate that has taken place since the issue first arose and as the relevant legal framework has been developed. It is thus necessary to look at the phenomenon from the time when it first surfaced until the present day, and to identify the NPS universe, from the point of view of both their appearance on the market and what they signify for the subjects who use, produce, or simply sell them. This in turn implies contextualizing and understanding the substances' significance in contemporary technological consumer societies, which are divided between the real and virtual planes on which individuals act, and singling out their importance for and impact on the various dimensions - current, political, scientific - of the discourse linked to the subject.

\section{METHODS}

We start with a brief overview of practical and ethical issues that were addressed related with the methodology. 
This article focuses on the Portuguese reality about NPS, but it arises from a transnational and interdisciplinary EU-funded research project, "NPS: Transnational project on different user groups, user characteristics, extent and patterns of use, market dynamics, and best practices in prevention - NPS-trans" (see Korf et al., 2018 and Van Hout et al., 2018 for a detailed description of the study methods). The project's data-collection process included a document-based analysis of each country's public policies on drugs, and a survey among NPS users.

Fieldwork occurred in 2016. Eligibility criteria among respondents for the survey were: recent NPS use (at least once in the past 12 months); resident of the participating countries; and 18 years or older. The final sample of recent NPS Portuguese users consists of 281 . The data were screened/cross-checked for errors and analyzed using spss V.24. Analysis was conducted using anonymized data and involved descriptive statistics, including frequencies and percentages.

In order to discuss the concept of NPs in legal terms but also for its users in Portugal, this article is based on data collected in the Portuguese country report (Henriques et al., 2018) and the responses of Portuguese NPS users. The results of this inquiry are noted in the next section and whenever necessary are complemented with European data.

\section{PUBLIC POLICIES AND NPS}

The NPS phenomenon is essentially tied to the emergence of smartshops in both Portugal (Calado, 2013) and other European countries - e.g. the Czech Republic, Romania, and Poland (Grund et al., 2016). Between 2007 and 2013, there were 60 physical shops located all around the country (mainland and islands, see Table 1) and another seven operating online (Goulão, 2013; Calado, 2013). During this period, these new psychoactive substances were usually bought from these specialized points of sale.

Identified and publicized as legal substances during the period in which such smartshops existed (no longer the case), this physical and virtual trade network tended to make the NPs that were sold in Portugal cheaper and easier to acquire than conventional drugs.

The ways in which these substances were initially referred to - "legal drugs", "smart drugs", "legal highs" - conveyed false ideas that their use was legal, riskfree, had positive effects, and consequently engendered a certain permissiveness. The authorities started looking for a more proper designation for these substances that would characterize the phenomenon and reverse the mistaken idea of a lack of harm that was associated with the substances at the time. In 
TABLE 1

Smartshops in Portugal, by District and Municipality (Calado, 2013)

\begin{tabular}{|c|c|c|c|}
\hline \multicolumn{2}{|c|}{ Number of shops by District } & \multicolumn{2}{|c|}{ Number of shops by Municipality } \\
\hline Aveiro & 1 & Aveiro & 1 \\
\hline Beja & 1 & Beja & 1 \\
\hline Braga & 2 & Braga & 2 \\
\hline Coimbra & 2 & Coimbra & 2 \\
\hline Évora & 2 & Évora & 2 \\
\hline \multirow{4}{*}{ Faro } & \multirow{4}{*}{6} & Albufeira & 2 \\
\hline & & Faro & 1 \\
\hline & & Lagos & 1 \\
\hline & & Portimão & 2 \\
\hline \multirow[b]{2}{*}{ Leiria } & \multirow[b]{2}{*}{2} & Caldas da Rainha & 1 \\
\hline & & Leiria & 1 \\
\hline \multirow{5}{*}{ Lisboa } & \multirow{5}{*}{22} & Cascais & 1 \\
\hline & & Lisboa & 14 \\
\hline & & Sintra & 3 \\
\hline & & Torres Vedras & 3 \\
\hline & & V. Franca de Xira & 1 \\
\hline \multirow{2}{*}{ Porto } & \multirow{2}{*}{5} & Porto & 4 \\
\hline & & Póvoa do Varzim & 1 \\
\hline \multirow{2}{*}{ Santarém } & \multirow{2}{*}{2} & Santarém & 1 \\
\hline & & Entroncamento & 1 \\
\hline \multirow{4}{*}{ Setúbal } & \multirow{4}{*}{5} & Almada & 2 \\
\hline & & Barreiro & 1 \\
\hline & & Montijo & 1 \\
\hline & & Setúbal & 1 \\
\hline Viana do Castelo & 1 & Viana do Castelo & 1 \\
\hline Vila Real & 2 & Vila Real & 2 \\
\hline \multirow{2}{*}{ Viseu } & \multirow{2}{*}{2} & Espinho & 1 \\
\hline & & Viseu & 1 \\
\hline Ponta Delgada & 1 & Ponta Delgada & 1 \\
\hline Total & 56 & & 56 \\
\hline
\end{tabular}

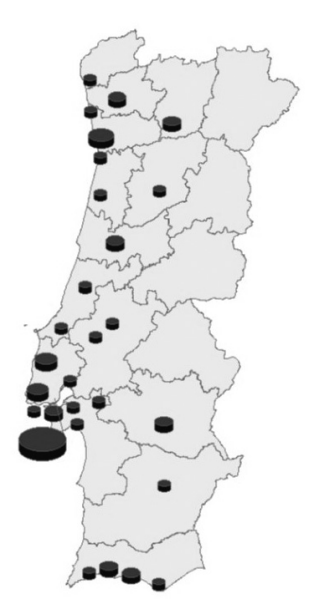


2010 the term "New Psychoactive Substances", a designation that incorporates a warning of the danger they entail (EMCDDA, 2011), was introduced in official, legal, and scientific discourse. However, the term was officially adopted in Portugal only in late 2012.

New Psychoactive Substances were thereafter defined as "a new narcotic or a new psychotropic, pure or in a preparation, which is not controlled by the 1971 United Nations Convention on Psychotropic Substances, but which may constitute a threat to public health comparable to that of the substances listed in those conventions" (see the SICAD website). ${ }^{1}$ In accordance with the same logic, smartshops were also termed "points of sale of new psychoactive substances" (Calado, 2013).

As to the legal framework for NPS, Law no. 13/2012 of 26 March 2012 amended Executive Law n. ${ }^{\circ}$ 15/93 of 22 January 1993 (the nineteenth time this Law was amended), which approved the legal regime governing the trafficking in and use of narcotics and psychotropic substances. The list of controlled substances was lengthened with the goal of adapting the official position in relation to the growth of the NPs phenomenon, and two NPs (mephedrone and tapentadol) were placed on the list of illicit substances. At around the same time the Autonomous Madeira Region experienced a substantial increase in the sale and use of NPS, and this led to the publication of the first regional legislation with rules on protecting the population and reducing the offer of "legal drugs" (Regional Legislative Decree n. ${ }^{\circ}$ 28/2012/M of 25 October 2012). All six shops in the Region were closed as a result.

This was an emerging phenomenon that changed considerably and continually. The information available on the effects of harm linked to the (ab)use of these new substances was always limited and confusing, with serious implications for public health. In this respect, the Portuguese Parliament recommended that the government "approve rules for the protection of public health and take measures in this regard. [Considering the] consensus that has formed on the danger of new psychoactive substances that are already known, and thus the likelihood that new administrative offences will be created in the future, it was seen as indispensable to establish anti-NPs health measures with immediate effect" (Resolution no. 5/2013 of 28 January 2013).

Shortly thereafter the government issued new legislation defining the legal regime governing the prevention of and protection against the advertising and sale of the new psychoactive substances that were already known and others that might appear on the market in the future (Executive Law n. ${ }^{\circ}$ 54/2013 of

1 http://www.sicad.pt/pt/paginas/search.aspx?k=Novas\%2oSubst\%C3\%A2ncias\%2oPsicoativas. 
17 April 2013). Under these new rules, it became unlawful to produce, import, export, advertise, distribute, sell, or possess NPs or make them available. The new legislation also included Ministerial Order n. ${ }^{\circ}$ 154/2013 of 17 April 2013 (referred to in Art. 3 of the Executive Law), which approved the list of new psychoactive substances and made 159 new substances illegal in Portugal. These changes in the law immediately led to the nationwide closure of the smartshops, and NPS are currently available only on the illicit market.

Alongside the official definition of new psychoactive substances, studies designed to monitor the situation were undertaken in/by various countries and organizations. We mention two examples in particular: "NPs in Europe", which focuses on NPS among so-called problematic drug-users; and "NPS:Trans", which is seeking to underatand NPS usage patterns by looking at three groups of users - online, recreational, and marginalized.

Another of the responses that accompanied the alterations in the law entailed the exchange of information, risk assessments, and NPs control between official European organizations. In particular, EMCDDA, the Council of Europe, and the European Union Agency for Law Enforcement Cooperation (EUROPOL) created a European Early-Warning System (Ews) designed to constantly flag and investigate the appearance of new psychoactive substances on the market, thereby making it possible to quickly transmit and swap information on the manufacture of, use of, and trade in NPs between the Member States.

It is important to note that the appearance on the drug markets of new substances that are not yet controlled by official national and international mechanisms and the latter's subsequent adaptation to the novelties is nothing new. What is new is the dynamic that the market has witnessed in recent years in which new substances are concerned. This dynamic has resulted from exploitation of the growing production capacity, not only in northern European countries (EMCDDA, 2016a), but also in China and India, as well as from the globalization of commercial exchanges and the role of the internet (Brandt, King, Evans-Brown, 2014).

\section{NPS: EVOLUTION, CATEGORIES, AND EFFECTS}

As mentioned above, the term "new psychoactive substances" refers to a vast and heterogeneous range of substances that are used for recreational and other purposes, and represent a growing and increasingly prevalent trend in the drug market. In 2009 -2014, the EU's Early-Warning System recorded 541 new psychoactive substances - a figure suggesting that novelties were appearing on the market in terms of both offer and demand. Seizures of NPs grew six fold 
between 2008 and 2013 (EMCDDA, 2015). In 2014 the Ews database recorded about 450 NPS (compared to 430 in 2013), 69 of which were reported for the first time (UNODC, 2015).

The diversity of NPS and the speed with which they appear explain why people have found it hard to categorize, identify, and list all of the NPS on the market. Although a whole range of bodies have sought to establish NPs typologies, even when different approaches and designations are attempted, concretely typifying NPS is currently one of the greatest challenges, despite the efforts that are being made to do so. The official United Nations Office on Drugs and Crime $^{2}$ website groups NPs into nine categories based on their predominant characteristics: aminoindanols; ketamine and phencyclidine-type substances; phenethylamines; piperazines; plant derivatives; synthetic cannabinoids; synthetic cathinones; tryptamines; and others. Although the European Monitoring Centre for Drugs and Drug Addiction also divides NPs into nine different groups - piperazines; benzodiazepines; arylamines; tryptamines; opioids; phenethylamines; synthetic cannabinoids; synthetic cathinones; and others its list includes new compounds. This way of organizing these substances highlights the role phenethylamines, cannabinoids, and synthetic cathinones have been playing in the European context (EMCDDA, 2016b). More recently, other ways of (re)organizing and presenting the groups of NPs that exist on the drug market have arisen. Examples include: synthetic cannabinoids; synthetic cathinones; piperazines; phenethylamines; ketamines and phencyclidine-type substances; tryptamines; benzofurans and synthetic opiates; and others (Zawilska, Andrzejczak, 2015).

In Portugal, official and regulatory definitions of NPs divide them into seven main groups: phenethylamines and their derivatives; piperazines and derivatives; cathinone derivatives; synthetic cannabinoids; cocaine derivatives/analogues; plants and their active principles; and others, including ketamine (Calado, 2013, p. 18). The case of ketamine illustrates another difficulty with classifying NPS, which is related to the fact that the reality of use in each country can influence the decision whether or not to include some substances in an NPS category. In Portugal, ketamine is officially included in the "others" group, but this is not so in other European countries, as we can see from the EMCDDA (2016b) classification.

Highlighting the speed with which new psychoactive substances arise, various authors (e.g. Zawilska, Andrzejczak, 2015) have been noting the existence of a "second generation of new substances" brought about by changes to the compounds used in NPS that have already been identified, which are 
made in order to try to circumvent legal and regulatory responses and amendments as they appear. The great variety and variability of the components in new psychoactive substances lead to large differences in terms of biological activity, pharmacological parameters, and effects on subjects, all of which have major implications for their definition, classification, and identification, both by agents involved at the political, social, chemical, medical, and other levels, and by users themselves.

These difficulties are compounded by another, which is linked to the different denominations used to identify new psychoactive substances. The fact is that NPS are referred to by a wide range of "monikers" (street and brand names) and the scientific names of compounds or chemical formulae. For example, there are products whose composition includes $\alpha$-PVP ( $\alpha$-pyrrolidinovalerophenone) with street names like "Ocean Breath", "Fire Ball", "Total speed", "Sensation”, "Speedway”, "Guarana Coco jumbo", "Energy 3 (NRG-3)”, and "Sextasy" (EMCDDA, 2015).

Given these difficulties with classifying and grouping these new substances, we propose a system that is based on the type of substance and its primary effects on the central nervous system, and is capable of encompassing the various categories of NPs: synthetic cannabinoids; synthetic stimulants; hallucinogens/psychedelics; and opiate-type synthetics.

Like many other drugs, the origins of synthetic cannabinoids lie in experimental laboratory work, in this case in the middle of the first decade of the $21^{\text {st }}$ century. The market for those substances then began to develop quickly and clandestinely, culminating in large numbers of products coming onto the market as cannabis alternatives (Castaneto et al., 2014). Over the course of 2014, the EU EWs identified 134 NPS of a synthetic cannabinoid type, which makes them the largest group of NPS available on the market. Current street names include "Spice" in Europe, "K2" in the Us, "Kronik" in Australia and New Zealand, and "Fidel-Mix" in Portugal (sICAD, 2013, 2014; Silva, 2012; Zawilska, Wojcieszak, 2014).

Synthetic cannabinoids are sold as herbal mixtures for smoking, and they are presented in packaging decorated with a variety of drawings and other images. The majority are produced in China and combine a mixture of herbs (e.g. melissa, mint, thymus, damiana) dissolved or pulverized in/with acetone, ethanol, or methanol. After drying, this compound is generally presented in the form of a powder (EMCDDA, 2015a). There is limited available information on the volume of synthetic cannabinoids that is consumed (EMCDDA, 2016b). In Portugal their use was more prevalent at the time of the smartshops, between 2007 and 2013 (SICAD, 2013; Silva, 2012), but it now appears to represent a smaller proportion of the overall market. In the "NPS:Trans" project 
in Portugal, around $20 \%$ of the respondents to the questionnaire-based survey (not representative of the general population) said that they had used synthetic cannabinoids in the last year.

The relative importance of these substances can be seen in the fact that by December 2015, the EU EWs had notified EMCDDA of the existence of 160 synthetic cannabinoids belonging to 14 chemical families (EMCDDA, 2016b). ${ }^{3}$ They are also important because EMCDDA has recorded a range of adverse occurrences with serious effects for human health as a result of the use of these substances (ibid). However, current knowledge about the pharmacological and toxicological effects of some synthetic cannabinoids is still limited - a limitation that is accentuated by the speed with which new variations and evolutions in the application of the substances appear on the market. One example is the inclusion of synthetic cannabinoids in the liquid used in electronic cigarettes and associated with the increasingly popular vaping phenomenon (ibid).

Turning to synthetic stimulants, cathinones are another large group of NPS that are available on the market. Synthetic cathinones and their derivatives comprise compounds that are chemically related to cathinone, which in the last decade was a class of substances that hit the market in a big way, namely in the form of recreational drugs and alternatives to psychostimulant substances that were already controlled (e.g. amphetamines, methamphetamines, and MDMA). Essentially presented as "plant fertilizers", "bath salts", or "research chemicals", these substances currently constitute the second-largest group of NPS available on the European market. Between 2005 and 2014 the EU EWS mechanism identified more than 80 cathinone-derivatives (EMCDDA, 2015a), with the most popular seeming to be mephedrone, methylone, and MDPV (3,4-dimethoxypyrovalerone).

Although many substances have been deliberately created in order to avoid drug legislation, others result from substances that were originally developed by the pharmaceutical industry and for one reason or another were either not put on the market, or were withdrawn from it. Many of the new substances that have recently entered the market are the result of the rediscovery of these pharmacological compounds and their commercial potential when offered on the drug market.

This picture includes synthetic cathinones that are not really recent. Mephedrone, for example, was first synthesized in 1929, PMMA in 1938, and

3 The European Monitoring Centre for Drugs and Drug Addiction (2016b) has published an interactive model for simulating the chemical composition of synthetic cannabinoids, which clearly displays their complexity - Interactive: demystifying the chemistry in http://www.emcdda. europa.eu/topics/pods/synthetic-cannabinoids\#panel2. 
MDPV in 1969 (UNODC, 2013). However, they became a major market presence only in the last decade. Mephedrone and its derivatives thus ended up being placed on the 1971 Drugs list on 16 April 2010, and on the Portuguese equivalent in 2012, with the implementation of Law n. ${ }^{\circ}$ 13/2012 of 26 March 2012, which added mephedrone and tapentadol to the annex of tables of psychoactive substances that are illegal in this country. Despite this, the substances' high level of popularity and the ease and speed with which they can be produced have meant that the new laws have not sufficed to keep them off the market, with the appearance of new compounds that are analogous to mephedrone, such as: 4-MEC; 4-MePpfvP; 4-MPPP; and PVP, which is analogous to MDPV (Zawilska, Andrzejczak, 2015).

Other NPS with stimulant psychoactive effects include the compounds 5and 6-APB, which appeared on the recreational drug market in 2010-2011 and are analogous (compounds with a similar, albeit slightly modified, molecular structure) to amphetamines, such as benzofuran. We also find aminorex analogs, such as 4,4'- DMAR and MDMAR. This compound was originally synthesized in pharmaceutical laboratories in the mid-1960s and was registered in Europe as an appetite suppressor in 1965, but was withdrawn shortly thereafter due to its collateral effects (above all, pulmonary hypertension). Aminorex then reappeared on the recreational drug market a few years later, and EMCDDA identified it in 2012 and included it on the NPS list in 2014 (EMCDDA, 2014). Available as powders or pills, many of these substances surfaced with names that are very similar to those of other, more conventional recreational designer drugs: "Playboy", "Mitsubishi", “Transformers", and so on. However, given their characteristics, they can appear in the form of ecstasy tablets. Their most common forms of use are oral ingestion and inhalation (EMCDDA, 2014a).

When it comes to hallucinogenic NPs, of particular note have been the appearance of compounds like the second generation of $-2 \mathrm{C}$ phenethylamines ( NBOMe), methoxetamine (MXE), diphenidine, and 2-methoxydiphenidine. The structural base underlying phenethylamine is found in various NPS - namely catecholamines and 2C-type drugs. Since 2C-B substances have become legally controlled, various compounds have been reinvented, synthesized, and placed on the market. This is the case of the phenethylamine substitutes (NBOMe) 25B-NBOMe (2C-B-NBOMe), 25C-NBOMe (2C-C-NBOMe), and 25I-NBOMe (2C-INвомe). Current street names include "N-Bomb", "Smile", and "CIMBI-5". Because they mimic the effects of conventional substances, some of them have been marketed as LSD substitutes - the case of the 25C-NBOMe and 25I-NBOMe compounds (EMCDDA, 2015; Zawilska, Andrzejczak, 2015). NBOMe-type substances can be found on the market in the form of pills, capsules, powder, 
liquid, spray, or packaged in small individual doses (Zawilska, Andrzejczak, 2015).

Within this group it is also important to mention Salvia Divinorum, whose active agent, salvinorin A, makes it a short-lived hallucinogen (Deluca et al., 2009; Calado, 2013). This substance can be found for sale as extracts from Salvia Divinorum leaves fortified with salvinorin A solution. ${ }^{4}$ Although Salvia Divinorum is permitted in some countries, it was made illegal in Portugal on 17 April 2013 (Ministerial Order 154/20135). As such, while it is not necessarily a new substance, the way in which it reappeared and has become part of new patterns of recreational use makes it a clear example of a new psychoactive substance.

Finally, we have the synthetic opiate-type substances, which include the compounds AH-7921 and MT-45. The former was synthesized and patented in 1976 as an opiate painkiller; the latter was also developed in the 1970s, by a Japanese pharmaceutical company. Other substances have appeared under the name "doxylam", and are made from the AH-7921 compound (EMCDDA, 2014b).

Our proposed generic classification is not necessarily as exhaustive as it might be if it were driven by purely chemical and pharmacological criteria. But it does have the benefit of simultaneously offering a general organization and a response to the pharmacological diversity, the complexity of the compounds, and the potential lack of knowledge associated with their rapid evolution and transformation. A situation that is further accentuated by the large number of substances and their generally widespread availability.

\section{NPS, THE INTERNET, AND THE VIRTUAL DIMENSION OF THE ILLICIT DRUG MARKET}

In the last decade the issue of drugs has changed in various ways, challenging researchers to stay abreast. Many of these changes have been driven by technological innovation, with impacts not only in terms of new forms of communication and interaction and the ways in which substances are sold, but also on the theoretical and empirical approaches adopted in recent investigation in this field. The focus on the role the internet is playing in the offer of and

4 The level of concentration of the bath determines the intensity of the effects, and can range from 5 times more to 60 times more.

5 "(145) Salvia Divinorum (and the respective constituent psychoactive elements salvinorin A and salvinorin B)", Plants and respective active constituent elements, Annex to Ministerial Order 154/2013 of 17 April 2013. 
demand for illicit drugs in general and new psychoactive substances in particular has been one of the main examples of this, but also one of the primary challenges when it comes to the more traditional dynamics, which are the ones that have been most often studied in recent years (new substances, trafficking routes, forms of acquisition, criminal networks) (Pires, Borges, Valente, 2015; EMCDDA, 2016).

The internet is democratizing access to information, ensuring that it remains accessible to all, while also providing new opportunities. In this digital scenario, substance users, dealers, researchers, and others with an interest in the subject of drugs all use technology and take advantage of easy access to the internet and mobile devices. The development of new means of information and communication has led to the emergence of discussion forums, webpages, applications, and other instruments in which the topic of drugs is discussed and substances are either promoted or argued against, and sometimes sold.

The problematic aspects of drugs are essentially linked to illicit markets, even in scenarios like the Portuguese one, in which use is not criminalized. Within this context the option for the parties to remain anonymous and avoid personal contact is both a self-protective strategy and an advantage within the dynamic of these online markets.

A number of studies have focused on the question of the online market for new psychoactive substances, based on the I-TREND - Internet Tools for Research in Europe on New Drugs software, which monitors online NPs shops. "I-TREND" has highlighted the virtual dimension of the drug phenomenon, and especially its capacity to adapt and respond to each country's or reality's markets, cultures, and usage habits (EMCDDA, 2016a). Other studies point to the advantages of this virtual dimension of the markets in terms of reducing interpersonal conflicts, inasmuch as interactions take place only online and on the basis of anonymity, and substances are potentially less likely to be adulterated because there tends to be a direct relationship between users and producers (Pires, Borges, Valente, 2015).

The changes in national, European, and international legislation seem to have contributed to the move from physical markets, such as smartshops, to the virtual market, with the latter in both its surface form (more accessible) and deep-web form (more restricted, can be seen as the web's "underworld" i. e. the part of the internet that cannot be accessed via conventional servers, but only from another particular type of website, using "hidden servers" and specific skills). NPS appear above all on the deep web, where they are available from the darknet or "cryptomarkets" (part of the deep web that is accessible only via specific browsers that protect users and conceal search and use histories; examples include Tor, which is short for "The Onion Router", a search 
engine that hides a computer's IP address - the primary way of identifying a subject who uses the internet - and thereby protects their privacy) (Pires, Borges, Valente, 2015; EMCDDA, 2016). The "dark" benefit is the fact that it is currently possible to conduct any type of transaction in this way, and that the location and real identity of the parties are irrelevant. Similarly, it is possible to share experiences of using a given substance in real time, thereby promoting it. There are no legal or other constraints in these commercial spaces (Aldridge, Décary-Hétu, 2014), identities are protected, financial transactions employ bitcoins or "litecoins", and communications are encrypted/encoded.

One of the first cryptomarkets to appear (2011) was the "Silk Road" - a sophisticated and innovative marketplace in which it was possible to acquire all kinds of substances at a wide range of prices. One of its innovative characteristics was that it required a whole assessment process designed to ensure customer satisfaction by means of ratings of/by producers, sellers, and end users. The goal of this feature of the marketplace was to establish relationships of trust between users and promote demonstrations of quality and reliability to potential customers (Aldridge, Décary-Hétu, 2014). The Silk Road was shut down in October 2013, but other platforms, such as Black Market Reloaded, The Armory, Evolution, and Agora have since appeared. In accordance with their mercantilist vocation, these types of platform have gradually improved the ways in which they monitor all the processes inherent in transactions, and are considered "resilient" markets - i. e. ones with the ability to adapt to new adversities and obstacles (EMCDDA, 2016a).

In short, cryptomarkets are a second generation of parallel networks that differ from the first ones by their main characteristics (Aldridge, Décary-Hétu, 2014; Van Hout, Bingham, 2013):

1) Payments are made using virtual currency (e.g. bitcoins).

2) Subjects are required to accept an anonymous protocol (e.g. Tor, or the Invisible Internet Project - I2P), thereby ensuring the absence of identifying elements and eliminating probabilities that the hidden servers will be traced and identified.

3) Incentives to keep transactions confidential, in such a way as to avoid the capture and sharing of information about illicit dynamics.

4) Use of an online assessment system, whereby the various parties can give their feedback about a given transaction, product, or delivery, thereby differentiating and highlighting certain quality criteria. 


\section{NPS, NEW USES, USERS, AND SIGNIFICANCE}

Recent studies suggest that NPS may be being sold as traditional substances (e.g. NBOMe as LSD), and that this increases the number of unintentional and/or unaware transactions, above all among certain groups, such as recreational and problematic drug users (Brandt, King, Evans-Brown, 2014; Grund et al., 2016).

In Portugal, both media pieces and scientific studies have shown the existence of a trend toward NPS use among minors (Silva, 2012; European Commission, 2011, 2014). However, there are still difficulties in producing knowledge in the NPs field, on the one hand due to its dynamic and rapid evolution, as described in this article, and on the other to a certain lack of knowledge about NPS displayed by psychoactive-substance users themselves.

These characteristics - the low level of knowledge, and the existence of some unintentional and unaware use - were also identified during the fieldwork conducted as part of the "NPS:Trans" study. These difficulties underscore the need to deepen both the knowledge and the discussion about data on the prevalence of NPS use, their effects, and representations about them, as gathered from users themselves.

The results of the questionnaire-based survey applied as part of the project between June and October 2016 indicate that 281 Portuguese persons (the respondents), the majority of whom were male and between 18 and 46 years of age, had already used at least one NPS - see Table 2.

This table presents the data collected on NPS use in a Portuguese context and developed within the framework of the broader European study. The

TABLE 2

NPS used

\begin{tabular}{lcc}
\hline \multirow{2}{*}{ NPS } & \multicolumn{2}{c}{ Frequency of use \% } \\
\cline { 2 - 3 } & $\begin{array}{c}\text { In the last } 12 \text { months, } \\
\text { but not in the last 30 days }\end{array}$ & In the last 30 days \\
\hline Mixture of herbs & 7.1 & 4.6 \\
Synthetic cannabinoids & 8.2 & 11.7 \\
Branded stimulants & 6.8 & 3.9 \\
Stimulants/Empathogens/ & 11.7 & 4.6 \\
Nootropics & 35.6 & 28.8 \\
Psychedelics & 10.0 & 3.6 \\
Dissociatives & 14.2 & 19.2 \\
Others & & \\
\hline
\end{tabular}


prevalence of hallucinogenic and stimulant-type substances confirms the results of other, earlier studies carried out in the same context, namely that of Pires, Borges and Valente (2015). However, all our fieldwork highlighted the fact that these are emerging substances with different origins and natures, and that there is thus little available information about their bioactive properties, including among users. This means that it is not possible to know the composition of the substances that are used, except from samples taken by the country's drug-testing service. In this respect, it is important to emphasize that users were asked whether they knew exactly what substance they were taking (e.g. what mixture of herbs, or what synthetic cannabinoid) and if they knew what the active agent was. The most common response for all the substances was "no". Having said this, and despite these difficulties in terms of recognition or an apparent lack of knowledge, $21.3 \%$ of respondents said their preferred substance was 2 Св (a hallucinogen).

These data once again confirm our above arguments on how difficult it is to achieve a conceptual definition of NPs. However, they also reinforce the idea that to the extent that many of these substances mimic the effects of conventional ones, they may be being sold and used as though they were the latter without their users really being aware of it. The drug-testing services around Europe, including in Portugal, that are present in recreational contexts - above all, festivals - seek precisely to collect and provide information on the substances in circulation and their degree of purity. Users are invited to submit their substances for analysis, and are given the results along with relevant information about reducing risks and minimizing harm (Giné, Espinosa, Vilamala, 2014; Brunt et al., 2017).

Although almost all of the studies that have been conducted to date suggest a relatively low level of prevalence of NPs use in recreational contexts, the tendency for the number of new substances to rise is likely to continue. This rising trend is having serious implications in terms of both the risks associated with use and the number of regular users, and is reflected in difficulties in finding responses that are appropriate to the problems (Brandt, King, Evans-Brown, 2014) (for example, at the level of the substitutional pharmacotherapy employed in cases of nicotine or heroin addiction, and of other therapeutic methods applied in cases of addiction to cocaine or amphetamine-type psychostimulants). Another of the related risks concerns certain forms of use, such as substance injection. We also know that there are NPs that are being consumed as though they were conventional substances, in situations of false labelling (when the substance does not correspond to what it is supposed to be, or to what is written on the packaging) and unintentional NPs users (Brandt, King, Evans-Brown, 2014; EMCDDA, 2015). This is both a warning and an additional 
challenge for the specialist staff who work in the risk-reduction field. It seems to us that one cannot dissociate the recent increase in the number of injected-substance users in Portugal from this context. ${ }^{6}$

Although, as we have already said, drug-users can be induced to consume NPS without their knowledge, and as such the level of prevalence of use may be being underestimated, the reasons given for using NPS do not present substantial differences compared to those given by users of conventional substances. In the "NPs:Trans" project, the reasons respondents gave for their uses are shown in Table 3.

Among this set of reasons, the ones that stand out are those most directly linked to hedonism, the search for self-knowledge, and a certain distancing from reality. An analysis of the phenomenon of new psychoactive substances in a globalized context should consider a range of mechanisms and forces that influence it. Some authors, such as Brandt, King, and Evans-Brown (2014) for example, argue that the use of psychoactive substances at present is likely to be one of the manifestations of the increasing medicalization of society that runs right through the debate on and understanding of the concepts of health, performance, fun, and consumption. The NPs phenomenon clearly goes beyond the designer drugs that marked the last decade of the $20^{\text {th }}$ and the first few years of the $21^{\text {st }}$ centuries, and is now taking on new shapes against the backdrop of an open market, with "legal highs" and "research chemicals".

Within the context of today's consumer societies, pleasure is taking on a market value, and as such, the discussion about NPs needs to incorporate two complementary dimensions. One concerns the improper use of prescription medicines as an emerging question of global import (Van Hout, 2014). The other involves dietary supplements, such as products that are widely available from e-commerce websites, online "pharmacy-food" shops, ${ }^{7}$ and fitness-related shops. In most cases they are presented as "natural", in order to exploit the generalized belief that these are healthy, safe consumer choices. The availability of these products warrants particular attention, because almost none of their producers and sellers are covered by substance monitoring systems (Griffiths, Evans-Brown, Sedefov, 2013).

6 In this respect, see e.g. the news item published in Visão magazine on 12 January 2017, available in Portuguese at http://visao.sapo.pt/actualidade/sociedade/2017-01-29-Os-novos -casais-ventosos.

7 The equivalent Portuguese term alicamentos (a junction of the words for food - alimentos and medicines - medicamentos) refers to products that are presented as medicines (Henriques, 2007). 
TABLE 3

Reasons for NPS use

\begin{tabular}{|c|c|c|}
\hline \multirow[b]{2}{*}{ Motivations* } & \multicolumn{2}{|c|}{ Frequency of use \% } \\
\hline & The majority & Almost always/ \\
\hline & of times & /Always \\
\hline To forget my worries & 3.2 & 1.8 \\
\hline To cheer me up when I'm in a bad mood & 4.6 & 2.5 \\
\hline Alleged legality & 1.8 & 4 \\
\hline To forget bad problems & 3.2 & 2.8 \\
\hline Because I like the feeling & 20.6 & 50.2 \\
\hline Poor quality of other drugs & 2.8 & 1.4 \\
\hline Because they give me a pleasant sensation & 20.6 & 46.6 \\
\hline Because they help me when I'm depressed or nervous & 3.6 & 5.0 \\
\hline To get to know myself better & 10.0 & 14.6 \\
\hline Because it's fun & 18.5 & 45.9 \\
\hline Because they help me enjoy a party & 21.0 & 29.9 \\
\hline To get high & 7.5 & 22.8 \\
\hline To be sociable & 5.0 & 4.3 \\
\hline Out of habit & 3.2 & 2.5 \\
\hline Because of the price & 1.4 & 1.8 \\
\hline So that people like me & 0.7 & 0.4 \\
\hline Because they make social events more fun & 15.7 & 16.4 \\
\hline Different or new experiences & 14.2 & 32.0 \\
\hline Because they improve parties or celebrations & 14.2 & 19.6 \\
\hline Because they're undetectable & 1.4 & 1.4 \\
\hline Because I feel more self-confident and sure of myself & 5.0 & 3.6 \\
\hline To be accepted in the group I like & 1.8 & 0.4 \\
\hline To expand my perception & 16.4 & 26.7 \\
\hline Conventional drugs are had to get & 2.8 & 2.5 \\
\hline To not feel excluded & 0.4 & 0.4 \\
\hline Because they help me be more creative and original & 8.5 & 10.0 \\
\hline Out of boredom & 1.8 & 1.1 \\
\hline To understand things in a different way & 10.0 & 18.9 \\
\hline To be more open to experiences & 12.5 & 25.3 \\
\hline To have fun & 15.3 & 47.3 \\
\hline To celebrate a special occasion with friends & 14.9 & 20.6 \\
\hline
\end{tabular}

\footnotetext{
* It is important to note that these motivations are broken down here in order to permit international comparisons within the broader framework of the "NPS:Trans" European study.
} 


\section{FINAL REMARKS}

The goal of the present article was to contribute to the discussion on a conceptual delimitation of new psychoactive substances, whose opaque nature has made advances more difficult on various levels: knowledge, policies, and intervention. To this end we began by situating the NPs phenomenon in terms of the relevant public policies; and then presented a proposed NPs classification based on the type of substance and its effects on the central nervous system. Albeit a general one, this way of organizing these substances is designed to respond to their pharmacological diversity and the complexity of their components.

In the case of NPS, the virtual dimension of the drug market seems to take on a particular and poorly known dynamic. This dimension is relevant from the point of view of both the offer of and the demand for NPs. With regard to the former, it is important to understand the routes, the circuits, the flows of information that are generated, the specific forms of transaction, and the (re)definition of the roles of the producer $v i s-\grave{a}$-vis the seller. When it comes to the latter, it is important to know the profiles of users, the patterns and prevalences of use, and the characteristics of the interactions and interaction networks that are established.

The data collected in relation to the Portuguese reality and within the overall framework of the "NPs:Trans" project have enabled us to illustrate the discussion with empirical information. In particular, the data on the NPS that are in use and the reasons for that use, which were gathered from users in recreational contexts and virtual environments, result in knowledge that can potentially impact the definition of strategies for both preventing and reducing risks and minimizing harm.

In conclusion, there is an indisputable need to increase knowledge about the nature and usage patterns of NPS and the potential risk associated with the substances, so as to then be able to identify potential areas of intervention and focal points for the development of preventive strategies (Giovanni et al., 2015). In this respect, we have pointed to a number of lines of action that deserve emphasis and are capable of complementing the updates to the substances' legal status as they gradually come about (Corazza et al., 2012; 2013). One entails monitoring online activities, which is essential if one is to map the dissemination of NPS. Another involves incorporating technological tools into specific prevention programs. Finally, the involvement of international and multidisciplinary partnership networks is especially important in light of the challenges created by the NPS problem, namely in terms of how novel the substances are and how fast they are expanding. 
In summary, while all these particularities of NPS are common to, and key factors in, their appearance in certain markets, and although the development of information and communication technologies is a reality on a global scale, it is nevertheless necessary to conduct a whole exercise designed to define and conceptualize NPs, because usage cultures and habits appear to vary from one country, one context, and one user group to another.

\section{REFERENCES}

WEBSITES

SICAD - Serviço de Intervenção em Comportamentos Aditivos e Dependências (Intervention Service for Addictive Behaviors and Dependencies), http://www.sicad.pt/PT/Cidadao/SubstanciasPsicoativas/Paginas/detalhe.aspx?itemId=19

UNODC - United Nations Office on Drugs and Crime, www.unodc.org

LEGISLATION

LAW N. ${ }^{\circ}$ 13/2012 OF 26 MARCH 2012 - http://www.sicad.pt/BK/Institucional/Legislacao/Lists/ SICAD_LEGISLACAO/Attachments/822/Lei_13_2012.pdf

EXECUTIVE LAW N. ${ }^{\circ}$ 15/93 OF 22 JANUARY 1993 - http://www.sicad.pt/BK/Institucional/Legislacao/Lists/SICAD_LEGISLACAO/Attachments/692/dl_15_93.pdf

REGIONAL LEGISLATIVE DECREE N. ${ }^{\circ}$ 28/2012/M OF 25 OCTOBER 2012 - http://www.sicad. pt/BK/Institucional/Legislacao/Lists/SICAD_LEGISLACAO/Attachments/839/ DLR_28_2012_M.pdf

RESOLUTION N. ${ }^{\circ}$ 5/2013 OF 28 JANUARY 2013 - http://www.sicad.pt/BK/Institucional/Legislacao/Lists/SICAD_LEGISLACAO/Attachments/846/RAR_5_2013.pdf

EXECUTIVE LAW N. ${ }^{\circ}$ 54/2013 OF 17 APRIL 2013 - http://www.sicad.pt/BK/Institucional/Legislacao/Lists/SICAD_LEGISLACAO/Attachments/849/DL_54_2013.pdf

MINISTERIAL ORDER N. ${ }^{\circ}$ 154/2013 OF 17 APRIL 2013 (AND ANNEXE) - http://www.sicad. pt/BK/Institucional/Legislacao/Lists/SICAD_LEGISLACAO/Attachments/85o/Portaria_154_2013.pdf

*

ALDRIDGE, J., DÉCARY-HÉTU, D. (2014), “Not an "eBay for drugs": the cryptomarket "Silk Road" as a paradigm shifting criminal innovation", retrieved from http://dx.doi.org/10.2139/ ssrn.2436643 [accessed on 15.05.2017]

Benschop, A., et al. (2017), New Psychoactive Substances: Transnational Project on Different User Groups, User Characteristics, Extent and Patterns of Use, Market Dynamics, and Best Practices in Prevention (NPS-transnational Project; HOME/2014/JDRU/AG/DRUG/7077), Final Report, Amsterdam, Bonger Institute of Criminology, University of Amsterdam. 
BRANDT, S.D., KING, L.A., EVANS brawn, M. (2014), “The new phenomenon”. Drugs Testing and Analysis, 6(7-8), pp. 587-597.

BRUNT, T. et al. (2017), "Drug testing in Europe: monitoring results of the trans European drug information (TEDI) project". Drugs Testing and Analysis, 9(2), pp. 188-198.

Calado, V. (2013), Novas Substâncias Psicoativas - O Caso da Salvia Divinorum, Lisbon, Serviço de Intervenção nos Comportamentos Aditivos e nas Dependências.

CAStAneto, M., et al. (2014), "Synthetic cannabinoids: epidemiology, pharmacodynamics and clinical implications". Drug Alcohol Dependence, 144, pp. 12-41.

Castells, M. (2002), Sociedade em Rede, Lisbon, Fundação Caloute Gulbenkian.

Corazza, O. et al. (2012), "Phenomenon of new drugs on the internet: the case of ketamine derivate methoxetamine". Human Psychopharmacology - Clinical \& Experimental, 27(2), pp. 145-149.

Corazza, O. et al. (2013), "Promoting innovation and excellence to face the rapid diffusion of Novel Psychoactive Substances in the EU: the outcomes of the ReDNet project". Human Psychopharmacology - Clinical \& Experimental, 28(4), pp. 317-323.

Deluca, P. et al. (2009), Salvia Delorium Report, London, Institute of Psychiatry, King's College London.

EMCDDA - European Monitoring Centre for Drugs and Drug Addiction (2011), Report on the Risk Assessment of Mephedrone in the Framework of the Council Decision on New Psychoactive Substances, Luxembourg, The Publications Office of the European Union.

EMCDDA - European Monitoring Centre for Drug and Drug Addiction (2014), European Drug Report 2014: Trends and Developments, Luxembourg, The Publications Office of the European Union.

EMCDDA - European Monitoring Centre for Drug and Drug Addiction (2014a), Europol Joint Report on a New Psychoactive Substance: Methoxetamine (2-(3-methoxyphenyl)-2(ethylamino)cyclohexanone), Luxembourg, The Publications Office of the European Union.

EMCDDA - European Monitoring Centre for Drug and Drug Addiction (2014b), Europol Joint Report on a New Psychoactive Substance: AH-7921, Luxembourg, The Publications Office of the European Union.

EMCDDA - European Monitoring Centre for Drug and Drug Addiction (2015), New Psychoactive Substances (NPS) in Europe. An Update from the EU Early Warning System, Luxembourg, The Publications Office of the European Union.

EMCDDA (2015a), Relatório Europeu sobre Drogas - Tendências e Evoluções, Luxembourg, The Publications Office of the European Union.

EMCDDA - European Monitoring Centre for Drug and Drug Addiction (2016), Relatório Europeu sobre Drogas, Luxembourg, The Publications Office of the European Union.

EMCDDA - European Monitoring Centre for Drug and Drug Addiction (2016a), The Internet and Drug Markets, Luxembourg, The Publications Office of the European Union.

EMCDDA - European Monitoring Centre for Drug and Drug Addiction (2016b), Perspetivas sobre Drogas - os Canabinoides Sintéticos na Europa, Luxembourg, The Publications Office of the European Union.

european commission (2011), Flash Eurobarometer - Youth Attitudes on Drugs, Brussels, European Commission.

european commission (2014), Flash Eurobarometer - Young People and Drugs, Brussels, European Commission. 
GINÉ, C. V., EsPinosa, I. F., vilamala, M. V. (2014), "New psychoactive substances as adulterants of controlled drugs. A worrying phenomenon?. Drug Test Anal, 6(7-8), pp. 819-824. GiovanNi, M. et al. (2015), "Novel psychoactive substances: use and knowledge among adolescents and young adults in urban and rural areas". Human Psychopharmacology - Clinical \& Experimental, 30(4), pp. 295-301.

Goulão, J. (2013), "Novas substâncias psicoativas". Boletim da Ordem dos Advogados, 101/102, pp. 36-37.

Griffiths, P., EVANS-Brown, M., SEDefov, R. (2013), "Getting up to speed with the public health and regulatory challenges posed by new psychoactive substances in the information age". Addiction, 108(10), pp. 1700-1703.

GRUND, J-P.C. et al. (2016), “The Emperor's new clothes? Findings from the NPs in Europe, EU rapid assessment and response study of consumption of New Psychoactive Substances among people who use drugs heavily in five EU member states". Adiktologie, 16(2), pp. 78-90.

Henriques, S. (2007), Imagem Mediática dos Consumos: Mediação do Jornalismo de Mercado na Construção Social dos Estilos de Vida - PhD dissertation, Lisbon, ISCTE-IUL.

HENRIQUES, S., SILVA, J. P., HSU, K. (2018), “Overview on new psychoactive substances in Portugal”. CIES $e$-WP n. ${ }^{\circ}$ 2017/2018, Lisbon, CIES-IUL.

KORF, et al. (2019), "How and where to find NPs users: A comparison of sampling methods in a cross-national survey among current users of new psychoactive substances. International Journal of Mental Health and Addiction. https://doi.org/10.1007/s11469-019-0052-8

Pires, C. V., BORGes, M., valente, H. (2015), "Netreach work in Europe: responses to developments on the dark web and the use of new psychoactive substances". In M. Wouters, J. Fountain (eds.), Between Street and Screen - Traditions and Innovations in the Drugs Field, Lengerich, Pabst Science Publishers, pp. 57-75.

SICAD (2013), Consumos, Representações e Perceções das Novas Substâncias Psicoativas entre Estudantes Universitários 2013, Lisbon, Serviço de Intervenção em Comportamentos Aditivos e Dependências.

SICAD (2014), Consumos, Representações e Perceções das Novas Substâncias Psicoativas entre Estudantes Universitários 2014, Lisbon, Serviço de Intervenção em Comportamentos Aditivos e Dependências.

Silva, J. (2012), As Representações Sociais das "Smart Drugs" - Uma Breve Descrição do Fenómeno - Master's Thesis, Lisbon, ISPA - Instituto Universitário (unpublished).

UNODC - United Nations Office on Drugs and Crime (2013), The Challenge of New Psychoactive Substances, Vienna, United Nations Office on Drugs and Crime.

UNODC - United Nations Office on Drugs and Crime (2015), Early Warning Advisory on New Psychoactive Substances, Vienna, United Nations Office on Drugs and Crime.

VAN hout, M. C., BINGHAM, T. (2013), “'Silk Road', the virtual drug marketplace: A single case study of user experiences”. International Journal of Drug Policy, 24(5), pp. 385-391.

VAN HOUT, M. C. (2014), "Kitchen chemistry: A scoping review of the diversionary use of pharmaceuticals for non-medicinal use and home production of drug solutions". Drug Test Anal., 6(7-8), pp. 778-787.

vAN HOUt, M. C., et al. (2018), "Health and social problems associated with recent Novel Psychoactive Substance (NPS) use amongst marginalised, nightlife and online users in six European countries". International Journal of Mental Health and Addiction, 16(2), pp. 480-495 . 
ZaWilska, J., wojCieszak, J. (2014), "Spice/K2 Drugs - more than innocent substitutes for marijuana”. International Journal of Neuropsychopharmacology, 17(3), pp. 509-525.

ZAWILSKA, J.B., ANDRZEJCZAK, D. (2015), "Next generation of novel psychoactive substances on the horizon - a complex problem to face". Drug and Alcohol Dependence, 157, pp. 1-17.

Received at 21-02-2018. Accepted for publication at 02-10-2019.

HeNriQues, S., GUerreiro, M. das D., SILVA, J. P. (2019), "New Psychoactive Substances: towards a conceptual delimitation”. Análise Social, 233, LIV (4. $\left.{ }^{\circ}\right)$, pp. 804-826.

Susana Henriques »Susana_Alexandra_Henriques@iscte-iul.pt »Centro de Investigação e Estudos de Sociologia (CIES-IUL), ISCTE-IUl » Edifício iscte, Av. das Forças Armadas - 1649-026 Lisboa, Portugal » https://orcid.org/oooo-0002-7506-1401.

Maria das Dores Guerreiro » maria.guerreiro@iscte.pt » Centro de Investigação e Estudos de Sociologia (Cies-iUl), Iscte-IUl » Edifício Iscte, Av. das Forças Armadas - 1649-026 Lisboa, Portugal » https:// orcid.org/oooo-0002-6990-5604.

Joana Paula Silva » jpaulapbrsilva@gmail.com » Centro de Investigação e Estudos de Sociologia (CIES-IUL), ISCTE-IUL » Edifício ISCTE, Av. das Forças Armadas - 1649-026 Lisboa, Portugal » https://orcid.org/oooo0001-7938-5094. 